\title{
Some Predictors of Perceived Support and Proximity in Students during COVID-19 Distance Learning
}

\author{
Sonja Pečjak ${ }^{a}$, Tina Pirc b, , Anja Podlesekº, Cirila Peklaj ${ }^{d}$
}

\author{
Received \\ Revised \\ Accepted \\ $\mathrm{DOI}$
}

9 June 2021

23 August 2021

17 September 2021

10.26822/iejee.2021.228

aSonja Pečjak, Department of Psychology, Faculty of Arts, University of Ljubljana, Slovenia

E-mail: sonja.pecjak@ff.uni-lj.si

ORCID: https://orcid.org/0000-0003-0402-3325

b; Corresponding Author: Tina Pirc,

Department of Psychology, Faculty of Arts, University of Ljubljana, Slovenia

E-mail: tina.pirc@ff.uni-lj.si

ORCID: https://orcid.org/0000-0002-9248-0608

${ }^{\circ}$ Anja Podlesek, Department of Psychology, Faculty of Arts, University of Ljubljana, Slovenia

E-mail: anja.podlesek@ff.uni-lj.si

ORCID: https://orcid.org/0000-0003-2987-8338

${ }^{d}$ Cirila Peklaj, Department of Psychology, Faculty of Arts, University of Ljubljana, Slovenia

E-mail: cirila.peklaj@ff.uni-lj.si

ORCID: https://orcid.org/0000-0002-1487-3078

\begin{abstract}
Due to the COVID-19 pandemic, distance learning and social isolation have dramatically changed the social and learning experiences of adolescents. Given that social isolation can adversely affect students' psychosocial well-being, our study examined the extent to which ICT competences, resilience, and individual types of contact with teachers and classmates contribute to the psychosocial well-being of lower secondary school students $(N=1,813)$ over an extended period of distance learning. The questionnaires were conducted in groups via videoconferences using the 1 ka application. The structural model showed that perceived proximity and support from teachers and classmates as indicators of psychosocial well-being were most strongly predicted by student resilience, teacher organization of group work, student contact with class teachers outside of regular school hours, and contact with classmates through online social networks. These findings have practical applications for teacher education and implementation in teacher practice.
\end{abstract}

\section{Keywords:}

COVID-19, Distance Learning, Students, Psychosocial Well-Being, Support, Proximity

\section{Introduction}

The COVID-19 pandemic has drastically changed the Much of life has come to a standstill, including the closing of educational institutions, the transition to distance learning, and the requirement to reduce interpersonal contact (i.e., maintain social distance). Slovenian students, similar to students in many other countries, had to engage in distance learning for a long period of time. For students, school is not only a place of academic learning, but also a place of socialization, connection with peers, friends, and adults, and a place where they receive both learning and emotional support from peers and teachers. Developing and maintaining students' social relationships with others therefore requires physical proximity between them - on the way to school, hanging out together in the schoolyard or during recess and in the classroom (van den Berg, 2015). All of these relationships are important for students' greater psychosocial well-being and adjustment (Allen et al., 2018; 
Law et al., 2013). The present study examined the effects of social isolation and a drastic reduction in direct interactions (mostly limited to individuals within the immediate family) on adolescents' psychosocial well-being.

\section{Components of Psychosocial Well-Being}

Psychosocial well-being is a superordinate construct that encompasses emotional or psychological wellbeing as well as social and collective well-being (Larson, 1996; Martikainen, 2002). It is synonymous with 'quality of life' as a whole, as it includes emotional, social and physical components. In the past, the concept was mainly used in clinical practice. For example, Engels' (1997) biopsychosocial model explains illness as the result of an interaction between mechanisms at the biological, psychological and social levels. In this context, psychological and social well-being play a protective role in the dynamic balance between health and illness (Fava \& Sonino, 2018). With Positive Psychology, well-being became the subject of intensive psychological research in the 1990s. Keyes (2007) identifies three components of psychological well-being: emotional or subjective well-being, psychological well-being, and social well-being. Wellbeing encompasses different areas in an individual's life. Davis (2019) writes about five domains, which we illustrate with the example of distance learning during the COVID-19 pandemic: (i) Emotional well-being is the ability to cope with stress while regulating negative emotions. For example, the student does not panic and remains calm when unable to connect with the teacher via videoconferencing, calls the teacher and informs them about the connection problem. (ii) Physical well-being is the ability to maintain physical condition through healthy lifestyle and good exercise habits. For example, after sitting at the computer, the student does some exercises to strengthen their spine, and in the afternoon exercises. (iii) Social well-being is the ability to communicate with others, develop meaningful relationships, and maintain a support network thathelps an individual to overcomeloneliness. For example, the student is in daily contact with their friends through social media and occasionally calls classmates. (iv) Workplace well-being is the ability to pursue one's interests and learning goals, leading to further education. The student completes learning tasks in the e-classroom (e.g., Moodle environment, Microsoft Teams) as assigned by the teacher. (v) Social well-being is the ability to actively participate in the community or environment in which the individual lives. For example, in situations where multiple people are present, the student behaves responsibly and adheres to safety measures that prevent the spread of the coronavirus. Davis (2019) emphasizes that ensuring that an individual achieves all of these types of wellbeing to some degree is necessary for overall wellbeing.

\section{Psychosocial well-being in students during the first wave of the COVID-19 pandemic}

There was little study of psychosocial well-being in students during the first wave of the COVID-19 pandemic in the spring of 2020. Studies focused primarily on academic issues, such as those related to learning processes (student motivation, opportunities to make connections or test knowledge at a distance, etc.) (e.g. König et al., 2020; Niemi \& Kousa, 2020). From a psychosocial perspective, studies on the perception of a pandemic as a stressful situation and on students' and teachers' reactions or adaptation to it predominated (Ellis et al., 2020; Ristić Dedić, 2020; Rupnik Vec et al., 2020). The results of the rare studies on the psychosocial aspects of distance education in the first wave of the epidemic showed the negative consequences of such education on various aspects of psychological well-being and mental health among primary, secondary school and university students. In a sample of Italian adolescents aged 13 to 20, Buzzi et al. (2020) found that adolescents' levels of general anxiety increased, with girls and younger adolescents being more anxious than others. Adolescents were anxious about the impact of distance learning on their learning, as well as changes in their social relationships, particularly relationships with friends. Just over a fifth reported less communication and meetings with friends, and at the same time an increase in communication with friends via online social networks, with girls significantly more likely to communicate with friends in this way. At the same time, adolescents reported that in addition to conversations with family members, conversations with peers and friends were most important in meeting their emotional and social needs. Ellis et al. (2020) reached a similar conclusion among Canadian adolescents with an average age of 17. They reported major concerns about distance learning, both in terms of its impact on learning performance and in terms of deterioration of relationships with peers and friends ( $41 \%$ had very strong concerns of this kind). At the same time, the study found that the reduction in the amount of time spent with friends was an important predictor of their feelings of loneliness. Ristić Dedič (2020) found that the biggest stressor for Croatian high school students was not being able to meet with friends in person. A survey of Slovenian high school students (Rupnik Vec et al., 2020) also showed that the biggest problem with distance learning was that they longed to see their classmates $(77 \%$ of students aged $9-12,65 \%$ of students aged $12-15$, and $54 \%$ of students aged 15-18). In general, girls experienced such feelings more than boys. Significant deterioration in psychosocial well-being was also found in studies of university students, who reported increased stress, anxiety, feelings of loneliness, and depression as a result of reduced social networks, lack of interactions, and less emotional support from peers and friends (Elmer et al., 2020; Eving et al., 2021). 
In summary, the results of studies from the first wave of school closures primarily show reductions in social, emotional, and occupational well-being. In our study, we focused mainly on the aspect of students' social and emotional well-being.

\section{Indicators and Correlates of Psychosocial Well-Being}

In school, students are involved in two important social systems - relationships with teachers and with classmates/peers. Perceived closeness and support from students and teachers, as well as feelings of loneliness or missing teachers and peers, can be considered indicators of students' social and emotional well-being. Perceived support and closeness is established through the student's social ties to other individuals, groups, and a larger community, such as the classroom (Cooke et al., 1988). Studies show a positive relationship between teacher support and learning skills (Patrick et al., 2007), intrinsic motivation (Ryan et al., 1994), and, by encouraging student involvement, student achievement (Klem \& Connell, 2004). Some studies highlight significantly greater teacher support for girls (Reddy et al., 2003), while other studies report equal teacher support for boys and girls (DeWit et al., 2010).

During COVID-19 distance learning, such support became even more important. Teachers needed to ensure that students remained engaged in learning despite their physical absence (following the teacher's explanations in the videoconference, finding an assignment in the e-classroom, completing it, and sending it to the teacher for review). In distance education, students are required to regulate their own learning and maintain motivation to achieve learning objectives, which they are often unable to do (Fryer \& Bovee, 2016). Therefore, in order to achieve the learning objectives, the teacher's support is needed more than in regular classes in school. In addition, emotional support is also important when students face various problems (e.g. boredom, frustration) during distance learning.

The period of distance learning combined with social isolation due to the containment of the spread of the virus also changed the social lives of children and young people dramatically. Overnight, their previous social networks, in which they had been involved in school and outside, dissolved. They maintained them, at least in part, through online social networks, satisfying their need to socialize in this way. Perceived peer support has been shown in previous research to be an important factor in maintaining adolescent mental health, and was particularly important during distance learning (Chaturvedi et al., 2021; Ye et al., 2020). In contrast, missing classmates and teachers is a feeling associated with loneliness, defined as a perceived discrepancy between actual and desired social relationships (Peplau \& Perlman, 1982). Loneliness may be due to the perceived or objective social isolation of students. It represents a negative aspect of students' psychosocial well-being. Most studies from the first wave of the pandemic reported that the respondents experienced feelings of missing someone (Ellis et al., 2020; Eving et al., 2021; Ristić Dedić, 2020). Such feelings have an important evolutionary function, signalling disruption to individuals and motivating them to restore relationships (Cacioppo et al., 2015). At the same time, these feelings can also lead to side effects, such as a decrease in trust in others, leading to defiant behaviour and even greater social isolation (Cacioppo et al., 2009), or a deterioration in mental health, including internalizing disorders (Ye et al., 2021). A friendly peer network and good family relationships are particularly important in preventing these feelings.

In addition to contact with others who provide social and emotional support, students' ability to cope with stressful situations, and thus their well-being, is highly dependent on their resilience (Scales et al., 2016). This refers to the individual's ability to respond positively and adapt successfully to novel or extraordinary, persistently difficult, or significant changes in circumstances (Masten et al., 2004). Resilience in children and adolescents has been found to be influenced by both their personality traits (internal sources of strength, such as high intellectual ability, self-esteem, and strong social skills) and protective factors in the environment as external sources of strength, such as a positive connection with at least one competent adult (a family member or teacher) or peer/friend whom the children or adolescents can trust while receiving their confidence, help, support, and structure (Grothberg Henderson, 2005; Luthar et al., 2000; Masten \& Obradović, 2006). Research shows that about one third of children are able to overcome problems that threaten their development at some point, but two thirds of them can be classified as a vulnerable group that needs concrete support from the environment (Garmezy \& Tellegen, 1984; Grothberg, 1995; Ye et al., 2021).

\section{The Aim of The Study}

During the COVID-19 pandemic, schools in Slovenia were closed twice for all primary and lower and upper secondary students - in the first wave of the pandemic from mid-March to June 2020, and in the second wave from mid-October to the end of January 2020. In the first wave, the initial focus was on developing the ICT competences of students and teachers to connect and implement the learning process in the first place, and on finding electronic ways to test knowledge. In the second wave, students' (and teachers') basic ICT competences were already 


\section{iejee $\approx$}

quite well developed, allowing them to focus more on learning (and teaching) itself. However, in the second wave students were exposed to prolonged social isolation for the second time, lasting for three months. This prolonged absence of students from school likely had an impact on their psychosocial well-being.

This study examined the extent to which ICT competences, resilience, and individual types of contact with teachers and classmates contribute to reducing lower secondary students' psychosocial well-being. We focused on indicators of students' emotional and social well-being, specifically the degree of perceived proximity and support and feelings of missing teachers and classmates. We examined the frequency of teachers' contact with students in the context of lessons when pursuing primarily learning goals (contact via e-classes, e-mail, and videoconferencing), as well as additional teacher contact with students about student problems related to both school and social isolation. We also investigated the relationship between student well-being and the frequency of group work in class (which facilitates the achievement of both learning and social integration goals) and the frequency of contact with classmates via online networks (where students meet their needs for belonging, acceptance, etc. in their free time).

Because perceived proximity and support or missing classmates or teachers are outcomes of students' interactions with classmates and teachers, we examined whether these constructs could be predicted by students' resilience, ICT competences and contact with teachers and classmates. We hypothesized a model in which ICT competence was assumed to have a positive association with psychosocial wellbeing by enabling students to use ICT communication tools effectively and to interact with teachers and classmates during class and with classmates in their free time during the second COVID-19 lockdown. We assumed positive associations between the extent of students' contact with teachers and peers/classmates and their psychosocial well-being, as social support is key to overcoming various difficulties and adapting positively to stressful situations (Borja et al., 2009; Helgeson \& Lopez, 2010; Sood et al., 2020). We also hypothesized that there is a positive relationship between resilience and students' psychosocial wellbeing, which is supported by numerous studies (Polizzi et al., 2020; Srivastava, 2011; Ye et al., 2020).

\section{Method}

\section{Participants}

Sample of the study included 1,813 students from 21 lower secondary schools from all statistical regions in Slovenia. There were 669 seventh graders (36.9\%), 526 eighth graders (29.0\%), and 618 ninth graders (34.1\%) in the sample. Of these, 868 were boys (47.9\%) and 945 were girls (52.1\%). There were no significant differences in gender structure between grades, $\chi^{2}(2)=1.21, p=$ 0.55 . The mean age of the students was 13.76 years ( $s d$ $=0.82$ ).

\section{Instruments}

Data were collected through an online survey.

Four items asked students about their ICT competences, i.e., how well they could browse the Internet and use e-classrooms, e-mail, and videoconferencing. Students responded on a 5-point scale (1 - very poor, 5 - excellent). The Cronbach's $\alpha$-coefficient of internal consistency was 0.85 .

Students' resilience was measured using the Slovenian adaptation of the Connor-Davidson Resilience Scale (CD-RISC-10) (Kavčič et al., 2021). Participants rated on a 5-point scale (1 - not at all, 5 - almost always) how they cope with stressful situations, obstacles, and changes (e.g., I can deal with whatever comes). The extracted factor explained $73.8 \%$ of the item variance and showed high reliability $(\alpha=0.96)$.

The extent of student contact was determined by the frequency of contact with teachers during lessons, additional contact with class teachers, and contact with classmates via online networks. Students rated on a 4-point scale (1 - (almost) never, 2 - once a week, 3 - several times a week, 4 - every day) how often, on average, they were in contact with teachers via e-classrooms, e-mail, and videoconferencing during the three-month distance learning period. Next, students rated on a 5-point scale (1 - once a month, 2 - every 14 days, 3 - once a week, 4 - 2 to 4 times a week, 5 - every day) how often they had contact with their classroom teacher in addition to the instructional time provided in the high school curriculum and mandatory home instructional time. These meetings typically involve discussion of problems related to learning and relationships with classmates, teachers, and others.

Finally, on a 6-point scale, students rated the average daily time spent in contact with classmates through electronic channels such as social media (FB, Instagram, Snapchat), text messages, phone calls, and video calls ( 1 - I had no contact, 2 - up to half an hour, 3 - half an hour to an hour, 4 - 1 to 2 hours, 5 2 to 4 hours, 6 - more than 4 hours). Additionally, on a 5 -point scale, students compared the frequency of group work during distance learning to that in school (1 - significantly less than in the classroom or not at all, 3 - same as in the classroom, 5 - significantly more than in the classroom).

Students' psychosocial well-being was measured as perceived closeness and support to classmates and teachers and feelings of missing them. We developed 
a 17-item questionnaire in which students compared on a 5-point scale how much they experienced different feelings during distance learning than they did at school (1 - much less than before, 3 - same as before, 5 - much more than before). Four items related to perceived closeness (two related to perceived closeness to classmates, e.g. I feel that I am close to my classmates, and two related to perceived closeness to teachers, e.g. I feel that I can turn to teachers when I need something. Nine items related to perceived support - three related to perceived support from classmates (e.g. I feel I can talk to my classmates about my feelings) and six related to perceived average support from the teacher and perceived support from the class teacher (e.g. I feel the teacher/class teacher cares about me). Four items measured how much there was a feeling of missing others, with two items related to missing classmates (e.g., I miss hanging out with classmates) and two related to missing teachers (e.g., I miss direct contact with teachers).

\section{Data Collection and Statistical Procedures}

The study was approved by the Ethics Commission of the Faculty of Arts, University of Ljubljana (application number 211-2020). Prior to data collection, informed consent was obtained from parents for their children's participation in the study. Data were collected via the 1KA web application (1ka, 2021) in the first half of January 2021. Students responded to the online questionnaire during group videoconferences with the assistance of school counsellors. Parental consent was obtained prior to collecting data from students. Structural equation modelling using the R lavaan package (Rosseel, 2012) was conducted to describe the relationships among the variables under study. The WLSMV estimator was used due to the discrete and largely nonnormally distributed manifest variables (see Table 1) and multivariate nonnormality (Mardia's bp1 estimate of multivariate skewness $=86.37, p<.001$; Mardia's bp1 estimate of multivariate kurtosis $=1789.41$, $p<.001$ ) was used.

Scale scores were calculated as the mean or median of responses on all scale items.

\section{Results}

The hypothesized model (Figure 1) showed a marginal fit to the data, $\chi^{2}(594)=1588.12, p<.001, \mathrm{CFI}=.90$, RMSEA $=.030,95 \% \mathrm{Cl}$ for RMSEA = .029-.032, SRMR = .043. This fit was achieved after the inclusion of two pairs of correlated uniqueness (of two items within the Teachers' Support and two items within the Resilience scale) suggested by the modification indices. The results for the measurement part of the model in relation to the latent variables studied are presented in Table 1.

Descriptive statistics for the scale scores are presented in the upper part of Table 2. The students in our sample were moderately resilient and felt very competent in using ICT. During the second wave of the COVID-19 pandemic they felt as supported and close to their classmates and teachers as they did before distance learning started (2.94), but they reported missing their classmates (3.94) and teachers more (3.33).

The lower part of Table 2 presents descriptive statistics for single indicator items related to different types of contact students had with their classmates and teachers. On average, students spent 2.57 hours a day in contact with classmates they met not only during mandatory e-learning, but also through online social networks, texting, phone calls, and video calls, but there was considerable variability in the data for this variable. Students also reported that their teachers were less likely to give them instructions for group work than they were in the pre-distance learning classrooms.

Students reported that their contact with teachers during distance learning was most often via videoconferencing and e-classrooms (Mdn was several times a week), but students were less likely to be contacted by their teachers via e-mail (Mdn was once a week). $41.8 \%$ of students reported having additional contact with their class teachers - half of them reported having meetings with teachers once every two weeks or once a month, and the other half had more regular additional contact.

\section{Figure 1}

The Resulting Structural Model of the Relationships Among ICT Competences, Resilience, Contact and Psychosocial Well-being

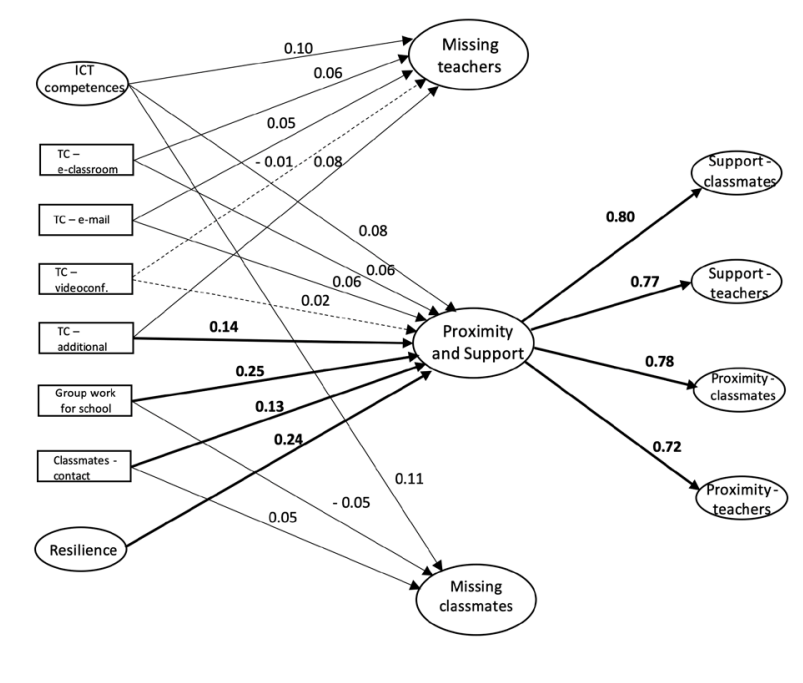

Note. $\longrightarrow \mathrm{p}<.001 ; \longrightarrow \mathrm{p}<.05 ;-\cdots$ non-significant $(\mathrm{p}>.05)$ TC - teacher contact; additional - teacher contact with students outside regular school hours

Figure 1 shows the relationships among the studied variables. According to the obtained path coefficients, student resilience, group work for school, contact with classmates, and additional contact with teachers contributed the most to students' perceived proximity and support from teachers and classmates (standardized path loadings were .24, .25, .13, and .14, 
Table 1

Descriptive Statistics for Items Included in the Model

\begin{tabular}{|c|c|c|c|c|c|}
\hline Item & M & $s d$ & $\gamma_{1}$ & $\gamma_{2}$ & $\lambda$ \\
\hline \multicolumn{6}{|l|}{ Resilience } \\
\hline Item 1 & 3.63 & 0.98 & -0.46 & -0.04 & 0.628 \\
\hline Item 2 & 3.56 & 0.93 & -0.26 & -0.24 & 0.745 \\
\hline Item 3 & 3.31 & 1.09 & -0.23 & -0.53 & 0.527 \\
\hline Item 4 & 2.94 & 1.15 & -0.04 & -0.66 & 0.622 \\
\hline Item 5 & 3.64 & 1.04 & -0.45 & -0.29 & 0.564 \\
\hline Item 6 & 3.86 & 0.99 & -0.58 & -0.17 & 0.679 \\
\hline Item 7 & 3.08 & 1.14 & -0.09 & -0.69 & 0.665 \\
\hline Item 8 & 3.52 & 1.01 & -0.35 & -0.24 & 0.716 \\
\hline Item 9 & 3.37 & 1.06 & -0.27 & -0.40 & 0.756 \\
\hline Item 10 & 3.38 & 1.14 & -0.36 & -0.55 & 0.617 \\
\hline \multicolumn{6}{|l|}{ ICT competences } \\
\hline Browsing the Internet & 4.35 & 0.83 & -1.42 & 2.33 & 0.737 \\
\hline Use of e-classrooms & 4.43 & 0.79 & -1.55 & 2.86 & 0.798 \\
\hline Use of videoconferencing & 4.58 & 0.72 & -2.03 & 4.98 & 0.765 \\
\hline Use of e-mail & 4.44 & 0.85 & -1.69 & 2.88 & 0.717 \\
\hline \multicolumn{6}{|l|}{ Missing classmates } \\
\hline I miss hanging out with classmates. & 4.04 & 1.07 & -1.07 & 0.57 & 0.889 \\
\hline I miss being able to talk to classmates. & 3.83 & 1.04 & -0.74 & 0.13 & 0.860 \\
\hline \multicolumn{6}{|l|}{ Missing teachers } \\
\hline I miss the live contact with the teachers. & 3.41 & 1.04 & -0.38 & -0.10 & 0.910 \\
\hline I miss being able to talk to teachers about something. & 3.25 & 0.95 & -0.12 & 0.24 & 0.809 \\
\hline \multicolumn{6}{|l|}{ Classmate support } \\
\hline I have a feeling my classmates care about me. & 2.78 & 0.80 & -0.33 & 1.12 & 0.583 \\
\hline $\begin{array}{l}\text { I have a feeling that one of my classmates can help me } \\
\text { with schoolwork (show me how to do something, or give me } \\
\text { advice). }\end{array}$ & 3.09 & 0.93 & -0.13 & 0.22 & 0.632 \\
\hline $\begin{array}{l}\text { I have a feeling that I can talk to one of my classmates about } \\
\text { my emotions, feelings. }\end{array}$ & 2.82 & 0.96 & -0.10 & 0.33 & 0.632 \\
\hline \multicolumn{6}{|l|}{ Teacher support } \\
\hline I have a feeling that teachers care about me. & 3.03 & 0.78 & -0.22 & 1.34 & 0.554 \\
\hline $\begin{array}{l}\text { I have a feeling that one of the teachers can help me with } \\
\text { schoolwork (show me how to do something, or give me } \\
\text { advice). }\end{array}$ & 3.03 & 0.85 & -0.10 & 0.56 & 0.612 \\
\hline $\begin{array}{l}\text { I have a feeling that I can talk to one of my teachers about } \\
\text { my emotions, feelings. }\end{array}$ & 2.58 & 0.87 & -0.47 & 0.05 & 0.591 \\
\hline I have a feeling that my class teacher cares about me. & 3.05 & 0.70 & -0.32 & 2.66 & 0.569 \\
\hline $\begin{array}{l}\text { I have a feeling that my class teacher can help me with } \\
\text { schoolwork (show me how to do something, or give me } \\
\text { advice). }\end{array}$ & 3.05 & 0.77 & -0.06 & 1.11 & 0.687 \\
\hline $\begin{array}{l}\text { I have a feeling that I can talk to my teacher about my } \\
\text { emotions, feelings. }\end{array}$ & 2.72 & 0.79 & -0.58 & 1.02 & 0.631 \\
\hline \multicolumn{6}{|l|}{ Classmate proximity } \\
\hline I have a feeling I can turn to classmates if I need anything. & 3.19 & 0.90 & 0.06 & 0.34 & 0.804 \\
\hline I have a feeling that I am close with my classmates. & 2.88 & 0.95 & 0.18 & 0.24 & 0.732 \\
\hline \multicolumn{6}{|l|}{ Teacher proximity } \\
\hline I have a feeling I can turn to my teachers if I need anything. & 3.13 & 0.82 & 0.05 & 0.91 & 0.704 \\
\hline I have a feeling that I am close with my teachers. & 2.82 & 0.78 & -0.25 & 1.44 & 0.796 \\
\hline
\end{tabular}


Table 2

Descriptive statistics for the constructs and single items included in the model

\begin{tabular}{|c|c|c|c|c|c|c|}
\hline & $N$ & $M / M d n^{b}$ & $s d / M A D^{\circ}$ & $\gamma_{1}$ & $\gamma_{2}$ & $\alpha$ \\
\hline Resilience & 1813 & 3.43 & 0.73 & -0.09 & 0.21 & 0.88 \\
\hline ICT competences & 1813 & 4.44 & 0.66 & -1.99 & 5.80 & 0.85 \\
\hline Missing classmates & 1813 & 3.94 & 0.99 & -0.92 & 0.47 & 0.87 \\
\hline Missing teachers & 1813 & 3.33 & 0.92 & -0.30 & 0.28 & 0.85 \\
\hline Proximity and support & 1813 & 2.94 & 0.50 & -0.30 & 1.78 & 0.85 \\
\hline Classmates contactb & 1813 & 1.50 & 1.50 & / & / & / \\
\hline Group work for school & 1813 & 2.19 & 1.01 & 0.78 & 0.14 & / \\
\hline $\mathrm{TC}^{\mathrm{a}}$ - videoconferencing ${ }^{\mathrm{b}}$ & 1813 & 3 & 1 & / & / & / \\
\hline TC $-e-m a i l^{b}$ & 1813 & 2 & 1 & / & / & / \\
\hline $\mathrm{TC}-\mathrm{e}$-classroom ${ }^{\mathrm{b}}$ & 1813 & 3 & 1 & / & / & / \\
\hline TC - additional ${ }^{d}$ contactb $^{b}$ & 757 & 3 & 1 & / & / & / \\
\hline
\end{tabular}

Note. ${ }^{\mathrm{a} T C}$ - teacher contact; ' Median was calculated; ${ }^{\mathrm{C}} \mathrm{MAD}$ - median absolute deviation from the Median; ${ }^{\mathrm{N}} \mathrm{Number}$ of students who reported contact with class teachers (in addition to the lessons and compulsory home class periods); $\gamma_{1}-s k e w n e s s, \gamma_{2}-e x c e s s$ kurtosis.

respectively). Slightly less influential, but still significant with regard to students' sense of proximity and support, were contact with teachers via e-classrooms and e-mail and their ICT competences. However, videoconferencing with teachers during COVID-19 distance learning did not contribute significantly to students' sense of proximity and support. We also found that students' ICT competences, their contact with teachers via e-mail and e-classrooms, and additional time they spent with their class teachers were significantly related to feelings of missing teachers. Similarly, ICT competences and contact with classmates via online social networks, phone or video calls were significantly related to feelings of missing classmates. However, group work for school negatively predicted feelings of missing classmates, and the effect was small but significant.

\section{Discussion}

This study examined the extent to which students' ICT competences, resilience, and various distance contact with teachers and classmates contributed to students' psychosocial well-being during distance learning in the second wave of the COVID-19 pandemic (late October 2020 to early February 2021). The construct of well-being was described using the latent variables of perceived proximity and support (which include perceived support and proximity from classmates and teachers), missing teachers, and missing classmates. The results provide support for our theoretical model.

Small but statistically significant positive path coefficients (ranging from .08 to .11) were found for the relationships between students' ICT competence and perceived support and proximity, and feelings of missing classmates and teachers. ICT competence was an important tool for students to maintain contact with classmates (especially during their free time) and teachers during the pandemic. Students rated their ICT competences very high, with an average score of 4.44 on a 5-point scale. Research shows that ICT competence reduced stress in adolescents even before the pandemic by enabling them to spend their free time online, where they gained a sense of greater social support (Manago et al., 2012; Nabi et al., 2013). However, in a time of social isolation during the pandemic, this competence was also important for maintaining students' psychosocial well-being by supporting communication with others. For healthy, functional development, adolescents need the contact with peers and adults that enables them to meet their needs for competence, autonomy, and connectedness (Ryan \& Deci, 2000) and that motivates them to learn.

In the model, the three indicators of students' psychosocial well-being were also predicted with different types of contact with classmates and teachers. During distance learning, this contact was limited and mostly restricted to electronic communication. Direct contact with classmates was limited to learning situations when teachers organized work in groups and to free time contact when they socialized through online social networks. Students reported that there was less group work during distance learning than at school. At the same time, the results showed that teachers' organization of work in groups was important for feelings of support and proximity with classmates (.25). In a situation of complete social isolation, work in groups was practically the only contact in the school context in which students could satisfy the need for social contact with peers and the need for acceptance by classmates, in addition to achieving learning goals. However, social acceptance by peers/classmates is particularly important in early adolescence (Wigfield et al., 2006). Our findings support the notion that the introduction of computer-based collaborative learning in distance education can promote better learning outcomes and motivate students to learn and interact (Chen et al., 2018). In studies that examined a 


\section{iejee}

traditional learning environment prior to the pandemic (e.g., Kyndt et al., 2013; Roseth et al., 2008), group work was found to be effective, especially when organized as collaborative learning. During the pandemic, group work enabled students to talk with their peers about the various hardships and stresses of the pandemic, share effective coping strategies, and support each other (Sood et al., 2020). In our study, higher perceived frequency of group work was also negatively related to feelings of missing classmates (-.05).

To a lesser but important extent, perceived feelings of support or proximity were related to students' contact with classmates via social networks (.13). A lower correlation was expected here because an individual's social network includes classmates as well as others who might provide support to the individual. Research with adults and university students has shown that individuals often seek social support in social networks when faced with various stressful experiences, and that lower levels of support received in these networks are also associated with poorer behavioural outcomes, such as post-traumatic stress disorder (Brewin et al., 2000; Ozer et. al., 2003).

Teachers' contact with students was generally tied to the implementation of the learning process to achieve academic goals. Teachers communicated with students indirectly (via e-classrooms and e-mail) or directly (via videoconferencing). It was surprising to see that both forms of indirect communication contributed more to students' perceived support and proximity (.06) than direct communication via videoconferencing (.02), since one would expect that direct, "live" communication between teachers and students through videoconferencing, which allows for verbal and nonverbal communication, would provide teachers with more opportunities to support students and would be perceived by students as providing better support. One possible explanation for these findings is that contact via e-mail may be more personal and show teachers' special concern for a particular student, whereas during videoconferencing teachers are likely to focus primarily on instruction (explaining and reviewing learning material). Effective two-way communication during videoconferencing may have been hindered by additional factors, e.g., some students were unable to connect to the videoconference, some lost their Internet connection during class, etc. In general, research on the use of videoconferencing during the pandemic has shown that such instruction is less personalized (Eving et al., 2021) and that students have negative attitudes toward using Zoom as a videoconferencing system for distance learning. They emphasize the negative impact of such instruction on their learning experience and motivation to learn, especially when it lasts for a long period of time (Serhan, 2020). It seems that the same was the case with the students in our sample.
Some class teachers had additional contact outside their home class periods, as reported by 770 of the student respondents (42\%). In these meetings, class teachers talked to students about the current situation regarding the pandemic, the difficulties they faced, and coping strategies. Although these meetings took place infrequently - on average once a month to once every two weeks - the results show that they contributed notably to students' perception of support and proximity (.14) and feelings of missing teachers (.08). According to the students, these meetings provided considerable relief, in the sense that they then recognized that their classmates were struggling with the same or similar difficulties, and that the teacher encouraged and reassured them, giving them hope that they would soon return to school. Perceived support can act as an incentive in digital learning situations (Fryer \& Bovee, 2016), which was important during the COVID-19 pandemic, especially given the decline in student motivation.

Our data also showed a positive association between resilience and students' psychosocial well-being (.24), which is consistent with findings from the first wave of the spring 2020 COVID-19 epidemic showing that university students' psychosocial well-being also depends on individual resilience (Polizzi et al., 2020; Srivastava, 2011; Ye et al., 2020). More resilient individuals find it easier to tolerate stressful situations, such as the COVID-19 pandemic, and to cope with persistent stressors. More resilient students perceive less distress and more support than less resilient students (Sood \& Sharma, 2020), and resilience, along with social support, has been shown to mediate between the stressful COVID-19 situation and acute stress problems (Ye et al., 2021).

\section{Conclusions}

In summary, the study shows that students' resilience, teachers' organization of group work, students' contact with class teachers outside regular school hours, and contact with classmates through online social networks contributed most to adolescents' psychosocial well-being during distance learning. According to Kiswardy (2013), the resilience of adolescents in distance learning could be enhanced by providing a safe and accepting learning and social environment, building a sense of belonging, enabling supportive peer relationships, creating opportunities for participation in class and other school activities, and providing learning opportunities for all students, especially those who need additional support and special forms of encouragement. While attending to the social integration processes among students (building belonging and supportive peer relationships) is primarily the responsibility of the class teacher under normal school conditions, it seems that all teachers should consciously attend to them during distance learning, along with school counsellors. The 
findings of this study suggest that it would be useful for teachers to organize student work in groups more frequently during distance learning, taking advantage of the already demonstrated positive effects of collaborative learning on both students' academic and social integration outcomes (Roseth et al., 2008). In addition, providing equal opportunities for all students and establishing clear rules for videoconferencing (e.g., that all students should be connected to a videoconference with a video feed) would likely be beneficial in facilitating students' twoway communication with teachers and classmates.

Our study has several limitations. First, the results reflect only the students' perspectives. It would be useful to contrast them with teachers' views in further research. Second, due to the constraints of the lockdown situation, our sample included only students whose parents provided online consent for their children to take part in our study, and thus it is very likely that we did not receive consent from some less ICT literate parents for their children to participate. In further research, it would be useful to obtain additional information about the content of contact (with both classmates and teachers) that affect feelings of perceived proximity and support, and to investigate why videoconferencing did not contribute to greater perceived support and proximity.

We can nevertheless conclude that the results of our study provide initial insight into the factors that contribute to the lower secondary students' perceived proximity and support, which is an important aspect of students' psychosocial well-being during distance learning. These findings may be a starting point for planning pre-service and in-service teacher education that would enable teachers to provide social support to their students and thus enhance their well-being.

\section{Acknowledgement:}

This work was supported from the Slovenian Research Agency (research core funding No. P5-0110).

\section{References}

1KA (Version 21.02.16) [software]. (2021). Ljubljana: Faculty of Social Sciences. https://www.1ka.si.

Allen, K., Kern, M. L., Vella-Brodrick, D., Hattie, J., \& Waters, L. (2018). What schools need to know about fostering school belonging: A metaanalysis. Educational Psychology Review, 30(1), 1-34. https://doi.org/10.1007/s10648-016-9389-8.
Borja, S. E., Callahan, J. L., \& Rambo, P. L. (2009). Understanding negative outcomes following traumatic exposure: The roles of neuroticism and social support. Psychological TraumaTheory Research Practice and Policy, 1(2), 118129. https://doi.org/10.1037/a0016011.

Brewin, C. R., Andrews, B., \& Valentine, J. D. (2000). Metaanalysis of risk factors for posttraumatic stress disorder in trauma-exposed adults. Journal of Consulting and Clinical Psychology, 68(5), 748766. https://doi.org/10.1037/0022-006X.68.5.748

Buzzi, C., Tucci, M., Ciprandi R., Brambilla, I., Caimmi, S., Ciprandi, G., \& Marseglia, G. L. (2020). The psycho-social effects of COVID-19 on Italian adolescents' attitudes and behaviors. Italian Journal of Pediatrics, 46-69. https://doi. org/10.1186/s13052-020-00833-4.

Cacioppo, J. T., Fowler, J. H., \& Christakis, N. A. (2009). Alone in the crowd: The structure and spread of loneliness in a large social network. Journal of Personality and Social Psychology, 97(6), 977991. http://dx.doi.org/10.1037/.

Cacioppo, J. T., Cacioppo, S., Cole, S. W., Capitanio, J. P., Goossens, L., \& Boomsma, D. I. (2015). Loneliness across phylogeny and a call for comparative studies and animal models. Perspectives on Psychological Science, 10(2), 202-212. http:// dx.doi.org/10.1177/1745691614564876.

Chaturvedi, K., Vishwakarma, D. K., \& Singh, N. (2021). COVID-19 and its impact on education, social life and mental health of students: A survey. Children and youth services review, 121, 105866. https://doi.org/10.1016/j.childyouth.2020.105866.

Chen, J., Wang, M., Kirschner, P. A., \& Tsai, C. C. (2018). The role of collaboration, computer use, learning environments, and supporting strategies in CSCL: A meta-analysis. Review of Educational Research, 88(96), 799-843. https:// doi.org/10.3102/0034654318791584.

Cooke, B.D., Rossmann, M.M., McCubbin, H.I., \& Patterson, J.M. (1988). Examining the definition and assessment of social support: A resource for individuals and families. Family Relations, 37(2), 211-216. https://doi.org/10.2307/584322

Davis, T. (2019, January 2). What Is Well-Being? Definition, Types, and Well-Being Skills. Psychology Today. https://www.psychologytoday.com/us/blog/ click-here-happiness/201901/what-is-wellbeing-definition-types-and-well-being-skills 


\section{iejee}

De Wit, D., Karioja, K., and Rye, B. (2010). Student perceptions of diminished teacher and classmate support following the transition to high school: are they related to declining attendance? School Effectiveness and School Improvement, 21(4), 451-472. https://doi.org/10.1 080/09243453.2010.532010.

Ellis, W. E., Dumas, T. M., \& Forbes, L. M. (2020). Physically Isolated but Socially Connected: Psychological Adjustment and Stress Among Adolescents During the Initial COVID-19 Crisis. Canadian Journal of Behavioural Science, 52(3), 177-187. http://dx.doi.org/10.1037/cbs0000215.

Elmer T., Mepham, K., \& Stadtfeld, C. (2020). Students under lockdown: Comparisons of students' social networks and mental health before and during the COVID-19 crisis in Switzerland. PLOS ONE 15(7): e0236337. https://doi.org/10.1371/ journal.pone.0236337.

Engel, G. L. (1997). From biomedical to biopsychosocial. Psychotherapy and Psychosomatics, 66(2), 5762. https://doi.org/10.1159/000289109.

Ewing, L. A., \& Cooper, H. B. (2021): Technologyenabled remote learning during COVID-19: perspectives of Australian teachers, students and parents, Technology, Pedagogy and Education, 30(1), 41-57. https://doi.org/10.1080/1 475939X.2020.1868562.

Fava, G. A., \& Sonino N. (2008). The Biopsychosocial Model Thirty Years Later. Psychotherapy and Psychosomatics, 77(1), 1-2. https://doi. org/10.1159/000110052.

Fryer, L. K., \& Bovee, H. N. (2016). Supporting students' motivation for e-learning: Teachers matter on and offline. The Internet and Higher Education, 30, 21-29. https://doi.org/10.1016/j. iheduc.2016.03.003.

Garmezy, N., \& Tellegen, A. (1984). Studies of stressresistant children: Methods, variables, and preliminary findings. Advances in applied developmental psychology, 1, 231-287.

Grothberg, E. (1995). A Guide to Promoting Resilience in Children: Strengthening the Human Spirit. http://resilnet.uiuc.edu/library/grotb95b.html.

Grothberg Henderson, E. (2005). Resilience for Tomorrow. Iguazu: International Council of Psychologists Convention.
Helgeson, V.S., \& Lopez, L. (2010). Social support and growth following adversity. In W.R. John, J.Z. Alex, \& J.S. Hall (Eds.), Handbook of Adult Resilience (pp. 309-330). The Guilford Press.

Kavčič, T., Avsec, A., \& Kocjan, G. Z. (2021). Psychological functioning of Slovene adults during the COVID-19 pandemic: does resilience matter? Psychiatric Quarterly, 92(1), 207-216.

Keyes, C. L. M. (2007). The Mental Health Continuum: From Languishing to Flourishing in Life. Journal of Health and Social Behavior, 43(2), 207-222. https://doi.org/10.2307/3090197.

Kiswardy, V. (2013). Analiza koncepta rezilientnosti v kontekstu vzgoje in izobraževanja. Andragoška spoznanja, 19(3), 46-64.

Klem, A. M., \& Connell, J. P. (2004). Relationships matter: Linking teacher support to student engagement and achievement. Journal of school health, 74(7), 262-273.

König, J., Jäger-Biela, D. J., \& Glutsch, N. (2020). Adapting to online teaching during COVID-19 school closure: teacher education and teacher competence effects among early career teachers in Germany. European Journal of Teacher Education, 43(4), 608-622. https://doi.or g/10.1080/02619768.2020.1809650

Kyndt, E., Raes, E., Lismont, B., Timmers, T., \& Cascallar, E. (2013). A meta-analysis of the effects of faceto-face cooperative learning. Do recent studies falsify or verify earlier findings? Educational Research Review, 10, 133-149. http://dx.doi. org/10.1016/j.edurev.2013.02.002.

Larson, J.S. (1996). The World Health Organization's definition of health: Social versus spiritual health. Social Indicator Research, 38(2), 181-192. https://doi.org/10.1007/BF00300458

Law, P. C., Cuskelly, M., \& Carroll, A. (2013). Young people's perceptions of family, peer, and school connectedness and their impact on adjustment. Journal of Psychologists and Counsellors in Schools, 23(1), 115-140. https://doi.org/10.1017/ jgc.2012.19.

Luthar, S. S., Cicchetti, D., \& Becker, B. (2000). The construct of resilience: A critical evaluation and guidelines for future work. Child development, 71(3), 543-562. 
Manago, A. M., Taylor, T., \& Greenfield, P. M. (2012). Me and my 400 friends: The anatomy of college students' Facebook networks, their communication patterns, and well-being. Developmental psychology, 48(2), 369. https:// doi.org/10.1037/a0026338.

Martikainen, P. (2002). Psychosocial determinants of health in social epidemiology. International Journal of Epidemiology, 31(6), 1091-1093. https:// doi.org/10.1093/ije/31.6.1091

Masten, A. S., \& Obradović, J. (2006). Competence and resilience in development. Annals of the New York Academy of Sciences, 1094(1), 13-27. https://doi.org/10.1196/annals.1376.003.

Nabi, R. L., Prestin, A., \& So, J. (2013). Facebook friends with (health) benefits? Exploring social network site use and perceptions of social support, stress, and well-being. Cyberpychology, 16(10), 721-727. https://doi.org/10.1089/cyber.2012.0521.

Niemi, H. M., \& Kousa, P. (2020). A case study of students' and teachers' perceptions in a Finnish high school during the COVID pandemic. International journal of technology in education and science, 4(4), 352-369. https:// doi.org/10.46328/ijtes.v4i4.167

Ozer, E. J., Best, S. R., Lipsey, T. L., \& Weiss, D. S. (2003). Predictors of post-traumatic stress disorder and symptoms in adults: a meta-analysis. Psychological bulletin, 129(1), 52 - 73. https://doi. org/10.1037/0033-2909.129.1.52.

Patrick, H., Ryan, A. M., \& Kaplan, A. (2007). Early adolescents' perceptions of the classroom social environment, motivational beliefs, and engagement. Journal of educational psychology, 99(1), 83-98. https://doi. org/10.1037/0022-0663.99.1.83.

Peplau, L. A., \& Perlman, D. (Eds.). (1982). Loneliness: A sourcebook of current theory, research, and therapy. Wiley.

Polizzi, C., Lynn, S. J., \& Perry, A. (2020). Stress and coping in the time of covid-19: pathways to resilience and recovery. Clinical Neuropsychiatry, 17(2), 59-62.

Reddy, R., Rhodes, J. E., \& Mulhall, P. (2003). The influence of teacher support on student adjustment in the middle school years: a latent growth curve study. Develpomental Psychopathology, 15(1), 119-138. https://doi.org/10.1017/S0954579403000075.
Ristić Dedić, Z. (2020). Pilot istraživanje učeničkih potreba i suočavanja s izazovima online nastave u ožujku 2020. godine (Preliminarno izvješće) - Serija IDIZ-ovi vidici 003. Institut za društvena istraživanja u Zagrebu.

Roseth, C. J., Johnson, D. W., \& Johnson, R. T. (2008). Promoting early adolescents' achievement and peer relationships: The effects of cooperative, competitive, and individualistic goal structures. Psychological Bulletin, 13(2), 233-246. https://doi. org/10.1037/0033-2909.134.2.223.

Rosseel, Y. (2012). lavaan: An R Package for Structural Equation Modeling. Journal of Statistical Software, 48(2), 1-36. https://www.jstatsoft.org/ v48/iO2/.

Rupnik Vec, T., Preskar, S., Slivar, B., Zupanc Grom, R., Deutsch, T., Ivanuš Grmek, M., Mithans, M., Kregar, S., Holcar Brunauer, A., Preskar, S., Bevo, V., Logaj, V., \& Musek Lešnik, K. (2020). Analiza izobraževanja na daljavo $\vee$ času epidemije Covid-19 $\vee$ Sloveniji [Analysis of distance education during the Covid-19 epidemic in Slovenia]. Partial report, July 2020. Zavod RS za šolstvo.

Ryan, R. M., \& Deci, E. L. (2000). Self-Determination Theory and the Facilitation of Intrinsic Motivation, Social Development, and WellBeing. American Psychologist, 55(1), 68-78. https://doi.org/10.1037/0003-066X.55.1.68.

Scales, P. C., Benson, P. L., Oesterle, S., Hill, K. G., Hawkins, J. D., \& Pashak, T. J. (2016). The dimensions of successful young adult development: A conceptual and measurement framework. Applied Developmental Science, 20(3), 150-174. https://doi.org/10. 1080/10888691.2015.1082429.

Serhan, D. (2020). Transitioning from face-to-face to remote learning: Students' attitudes and perceptions of using Zoom during COVID-19 pandemic. International Journal of Technology in Education and Science (IJTES), 4(4), 335-342.

Sood, S. \& Sharma, A. (2020). Resilience and Psychological Well-Being of Higher Education

Students During COVID-19: The Mediating Role of Perceived Distress. Journal of Health Management, 22(4), 606-617. https://doi. org/10.1177/0972063420983111.

Srivastava, K. (2011). Positive mental health and its relationship with resilience. Industrial Psychiatry Journal, 20(2), 75-76. https://doi. org/10.4103/0972-6748.102469. 
Tiego, J., Testa, R., Bellgrove, M. A., Pantelis, C., \& Whittle, S. (2018). A hierarchical model of inhibitory control. Frontiers in psychology, 9, 1339. https:// doi.org/10.3389/fpsyg.2018.01339.

Van den Berg, Y. H. M. (2015). Peers in proximity. New perspectives on interpersonal processes in the classroom (Doctoral dissertation, [Sl: sn]).

Wigfield, A., Byrnes, J. P., \& Eccles, J. S. (2006). Development during earlyand middle adolescence. In P. A. Alexander \& P. H. Winne (Eds.), Handbook of educational psychology (pp. 87-105). Mahwah, NJ: Erlbaum.

Ye, Z., Yang, X., Zeng, C., \& Li, X. (2020). Resilience, Social Support, and Coping as Mediators between COVID-19-related Stressful Experiences and Acute Stress Disorder among College Students in China. Applied Psychology: Health and Wellbeing, 12(4), 1074-1094. https://doi.org/10.1111/ aphw.12211. 